Brief Report

\title{
Knowledge, source of information, and perception of Portuguese medical students and junior doctors of infection control precautions
}

\author{
David Peres MD, MPH ${ }^{\mathrm{a}, *}$, Milton Severo PhD ${ }^{\mathrm{b}, \mathrm{c}, \mathrm{d}}$, Maria Amélia Ferreira MD, PhD ${ }^{\mathrm{b}}$ \\ a Infection and Antibiotic Resistance Control Unit, Pedro Hispano Hospital, Senhora da Hora, Portugal \\ b Department of Medical Education and Simulation, Faculty of Medicine of University of Porto, Porto, Portugal \\ ${ }^{c}$ Clinical Epidemiology, Predictive Medicine and Public Health Department, Faculty of Medicine of University of Porto, Porto, Portugal \\ ${ }^{\mathrm{d}}$ Institute of Public Health of University of Porto, Porto, Portugal
}

Key Words:

Knowledge

source information

perception

medical students

junior doctors

infection control precautions

\begin{abstract}
Medical education should include infection control precautions (ICPs). Portuguese medical students showed reasonable knowledge in ICPs; however, contact isolation and glove and mask use should be reinforced. Only $25 \%$ referred to the curriculum as the most important information source. There was a positive association between academic year $(P=.032)$, previous training in ICPs $(P=.016)$, and knowledge. Main strategies proposed to acquire competences in ICPs were bedside teaching (26.9\%) and curriculum and bedside teaching (20.2\%).

(C) 2016 Association for Professionals in Infection Control and Epidemiology, Inc. Published by Elsevier
\end{abstract} Inc. All rights reserved.
Health care-associated infections are a major public health problem and are associated with substantial morbidity, mortality, and costs. A reason for this is differential behavior between recommendations and daily practice. ${ }^{1}$ Compliance to infection control precautions (ICPs), designed to prevent transmission of infectious agents, is internationally suboptimal and has significant implications for staff, patient, and environment safety. ${ }^{2}$ Recently, Portuguese health authorities have recommended that the pre- and postgraduation curricula in health sciences should include ICP. ${ }^{3}$

\section{METHODS}

\section{Subjects and sampling}

Subjects included fifth- and sixth-year students and junior doctors (interns) from the Faculty of Medicine of University of Porto. In Portugal, after medical school, students have to complete 1 year of internship before entering a residency program. Participants were invited, through e-mail, to complete an online questionnaire.

\footnotetext{
* Address correspondence to David Peres, MD, MPH, Comissão de Controlo de Infeção e Resistência aos Antimicrobianos, Hospital Pedro Hispano, Rua Dr Eduardo Torres, 4454-509 Matosinhos, Portugal.

E-mail address: david.r.peres@gmail.com (D. Peres).

Previous Presentation: Presented in part as a poster at the 21st Infection and Sepsis Symposium, March 8, 2016, Porto, Portugal.

Conflicts of Interest: None to report.

Additional Information: This study is part of a Master's thesis in Medicine of Faculty of Medicine, University of Porto.
}

\section{Questionnaire design}

The questionnaire was structured in the following 4 parts: (1) participant characteristics; (2) knowledge in ICPs (12 multiple choice questions with 1 correct answer), adapted from Sax et $\mathrm{al}^{4}$; (3) sources of information, based on Amin et $\mathrm{al}^{5}$; and (4) perception about contribution of the academic curriculum to their knowledge in this area (5 questions on a Likert scale), based on Amin et al. ${ }^{5}$

\section{Statistical analysis}

In knowledge scores, a correct answer was classified with 1 point (score range, 0 -12). In the perception scores of curriculum adequacy, each of the 5 items ranged from 1 (strongly disagree) to 5 (strongly agree), with a total score range of 5-25. Two independent sample $t$ tests or analyses of variance compared the means of knowledge and perception scores. The significance level was fixed at 0.05 .

\section{RESULTS}

\section{Overall population}

The response rate for the target population was $25.3 \%(\mathrm{~N}=223)$. The average age was 25.2 years (range, $21-48$ years), and $70 \%$ were women. Regarding academic year, $38.1 \%$ were students from the fifth year, $33.2 \%$ were from the sixth year, and $28.7 \%$ were junior doctors (Table 1). 
Knowledge in ICPS

The value of the Cronbach $\alpha$ test was 0.43 . The mean of the correct answers was $9.35 \pm 1.65$. The vast majority identified correctly the main purpose of hand hygiene (97.3\%), risk-guided application of a preventive strategy (97.3\%), and ubiquitous risk in body fluids (96.4\%). On the other hand, only $61 \%$ answered correctly about glove use, $59.2 \%$ for mask indication, and $29.6 \% \mathrm{knew}$ adequate procedures for contact isolation. Regarding participant characteristics, there was a positive association between academic year and knowledge in ICPs $(9.10 ; 9.24 ; 9.79 ; P=.032)$ and in previous training in ICPs and knowledge ( 9.16 vs $9.71 ; P=.016$ ) (Table 1 ).

\section{Source of information}

We found a variety of opinions related to the most important source of information for infection control knowledge (Table 1), in which $31.4 \%$ referred to bedside practice, $28.3 \%$ referred to bedside teaching, $25 \%$ referred to the curriculum, and $15.2 \%$ referred to self-learning.

\section{Perception of curricular adequacy}

The value of the Cronbach $\alpha$ test was 0.48 . The mean score of answers indicating curricular adequacy was $11.68 \pm 3.02$. Half of the students disagreed with that statement that current curriculum provides enough information on ICP (50.2\%), and more than half (53.7\%) disagreed that training sessions about ICPs are provided to medical students (Table 2). They admitted the need to improve in this area
(51.1\% indicated agree and 38\% indicated strongly agree to the need to receive training in ICPs). Those who declared that their main source of information was self-learning are the most dissatisfied with the curriculum $(P=.001)$ (Table 1$)$. No association was found between perception of curricular adequacy and knowledge in ICPs $(R=-0.015$, $P=.822$ ). When asked about the strategies to acquire competences in ICPs, $26.9 \%$ thought bedside teaching as the best, followed by $20.2 \%$ that preferred a combination of curriculum and bedside teaching; $15.7 \%$ would prefer to learn through bedside teaching and practice.

\section{DISCUSSION}

Medical students have earlier contact with patients in their training, and this can be a challenge for these future doctors. A study reported that $58 \%$ did not know the indications for alcohol-based handrub, and 35\% were unaware of correct glove use. ${ }^{7}$ In our study there were also some issues with poor results as glove and mask use and procedures for contact isolation. Legeay et al reported poor knowledge of medical students in ICPs, especially regarding personal protective equipment before providing care for isolated patients. They found that students in final study years were associated with better scores. ${ }^{8}$ These results are according to our results: there was a positive association between academic year and knowledge in ICPs. Another study reported that knowledge in this area decreases as the time since undergraduate training increases. They explained that this is the result of the recent introduction of this topic in basic training; therefore, the new generation had newer concepts. ${ }^{4}$ In contrast with what we obtained, Tavolacci et al

Table 1

Knowledge and perception of curricular adequacy scores related to infection control precautions, according to participant characteristics

\begin{tabular}{|c|c|c|c|c|c|}
\hline \multirow[b]{2}{*}{ Characteristic } & \multirow[b]{2}{*}{$\mathrm{n}(\%)$} & \multicolumn{2}{|c|}{ Knowledge score } & \multicolumn{2}{|c|}{ Perception of curricular adequacy score } \\
\hline & & Mean \pm SD & $P$ value & Mean \pm SD & $P$ value \\
\hline Total & $223(100)$ & $9.35 \pm 1.65$ & & $11.68 \pm 3.02$ & \\
\hline \multicolumn{6}{|l|}{ Age (y) } \\
\hline$\leq 24$ & $140(62.8)$ & $9.29 \pm 1.74$ & .454 & $11.63 \pm 3.11$ & .756 \\
\hline$>24$ & $83(37.2)$ & $9,46 \pm 1.50$ & & $11.76 \pm 2.88$ & \\
\hline \multicolumn{6}{|l|}{ Sex } \\
\hline Female & $156(70.0)$ & $9.45 \pm 1.50$ & .173 & $11.74 \pm 2.79$ & .680 \\
\hline Male & $67(30.0)$ & $9.12 \pm 1.96$ & & $11.54 \pm 3.50$ & \\
\hline \multicolumn{6}{|l|}{ Academic year } \\
\hline Fifth year & $85(38.1)$ & $9.10 \pm 1.60$ & .032 & $11.53 \pm 2.97$ & .770 \\
\hline Sixth year & $74(33.2)$ & $9.24 \pm 1.69$ & & $11.66 \pm 2.92$ & \\
\hline Intern & $64(28.7)$ & $9.79 \pm 1.62$ & & $11.89 \pm 3.21$ & \\
\hline \multicolumn{6}{|c|}{ Premedical health care worker } \\
\hline No & 209 (93.7) & $9.34 \pm 1.65$ & .604 & $11.72 \pm 3.06$ & .476 \\
\hline Yes & $14(6.3)$ & $9.08 \pm 1.62$ & & $11.08 \pm 2.35$ & \\
\hline \multicolumn{6}{|c|}{ Ever had infection control training } \\
\hline No & $146(65.5)$ & $9.16 \pm 1.69$ & .016 & $11.44 \pm 3.07$ & .104 \\
\hline Yes & $77(34.5)$ & $9.71 \pm 1.52$ & & $12.13 \pm 2.88$ & \\
\hline \multicolumn{6}{|c|}{ Most important source of information for infection control knowledge } \\
\hline Self-learning & $34(15.2)$ & $9.12 \pm 2.21$ & .478 & $9.94 \pm 3.22$ & .001 \\
\hline Curriculum & $56(25.1)$ & $9.16 \pm 1.64$ & & $12.36 \pm 3.01$ & \\
\hline Bedside teaching & $63(28.3)$ & $9.43 \pm 1.57$ & & $12.16 \pm 2.80$ & \\
\hline Bedside practice & $70(31.4)$ & $9.54 \pm 1.41$ & & $11.54 \pm 2.83$ & \\
\hline
\end{tabular}

Table 2

Perception of medical students of current curricular adequacy and training needs in infection control precautions

\begin{tabular}{|c|c|c|c|c|c|}
\hline Statements & Strongly disagree & Disagree & Neutral & Agree & Strongly agree \\
\hline Current curriculum provides enough information on ICPs & $32(14.1)$ & $114(50.2)$ & $25(11.0)$ & $52(22.9)$ & $4(1.8)$ \\
\hline Training sessions about ICPs are provided to medical students & $34(15.0)$ & $122(53.7)$ & $33(14.5)$ & $37(16.3)$ & $1(0.4)$ \\
\hline Tutors provided us enough information on ICPs before clinical rotations & $25(11.0)$ & $90(39.6)$ & $49(21.6)$ & $60(26.4)$ & $3(1.3)$ \\
\hline I learned about ICPs using case scenarios and simulations & $49(21.6)$ & $111(48.9)$ & $29(12.8)$ & $37(16.3)$ & $1(0.4)$ \\
\hline I need to receive training on ICPs & $0(0)$ & $4(1.8)$ & $19(8.4)$ & $116(51.1)$ & $88(38.8)$ \\
\hline
\end{tabular}

NOTE. Values are $\mathrm{n}(\%)$. Adapted with permission from Amin et al. ${ }^{6}$

$I C P$, infection control precaution. 
found that $86.7 \%$ of the 250 French health care students inquired stated the curriculum was the most important source of knowledge of ICPs. ${ }^{6}$

In the present study, we found that students who were more unhappy with the curriculum were the ones who admitted to having self-learning as their main source of information. A Portuguese study concluded about the relevance of role models and mentors as key factors in teaching hand hygiene to medical students. ${ }^{9}$ In fact, Frenk et al defended that coaching, instruction, and role models are important for the development of major attributes of professional behavior, identity, and values. ${ }^{10}$

Our study has some limitations, such as the population studied not being representative of all Portuguese medical students (we studied a sample of 1 of the 8 Portuguese medical schools). Another limitation is that knowledge does not necessarily translate into attitude and practice.

\section{CONCLUSIONS}

Our study revealed reasonable knowledge in basic concepts of ICPs. However, this sample of Portuguese medical students and junior doctors perceived deficiencies in curriculum and training in this area, especially related to contact isolation and glove and mask use. It is our opinion that implementation of World Alliance for Safer CareWHO Patient Safety Curriculum Guide for Medical Schools, ${ }^{11}$ in Portuguese faculties of medicine, with a combination of lectures and bedside teaching sessions, would improve the competences of future doctors in infection control and patient safety areas.

\section{References}

1. Yokoe DS, Anderson DJ, Berenholtz SM, Calfee DP, Dubberke ER, Ellingson K, et al Introduction to "A compendium of strategies to prevent healthcare-associated infections in acute care hospitals: 2014 updates". Infect Control Hosp Epidemiol 2014;35(Suppl 2):S1-5.

2. Gammon J, Morgan-Samuel H, Gould D. A review of the evidence for suboptimal compliance of healthcare practitioners to standard/universal infection control precautions. J Clin Nurs 2008;17:157-67.

3. Directorate-General of Health. Portugal- Infection and Antibiotic Resistance Control and Prevention in numbers - 2014. Lisbon (Portugal): Infection and Antibiotic Resistance Control and Prevention Programme; 2015.

4. Sax H, Perneger T, Hugonnet S, Herrault P, Chraïti MN, Pittet D. Knowledge of standard and isolation precautions in a large teaching hospital. Infect Control Hosp Epidemiol 2005;26:298-304.

5. Amin TT, Al Noaim KI, Bu Saad MA, Al Malhm TA, Al Mulhim AA, Al Awas MA Standard precautions and infection control, medical students' knowledge and behavior at a Saudi university: the need for change. Glob J Health Sci 2013;5:11425.

6. Tavolacci MP, Ladner J, Bailly L, Merle V, Pitrou I, Czernichow P. Prevention of nosocomial infection and standard precautions: knowledge and source of information among healthcare students. Infect Control Hosp Epidemiol 2008;29:642-7.

7. Mann CM, Wood A. How much do medical students know about infection control? J Hosp Infect 2006;64:366-70

8. Legeay C, Thépot-Seegers V, Groh M, Pilmis B, Zahar JR. Medical students knowledge of infection control and prevention: factors associated with better results and room for improvement. Am J Infect Control 2015;43:1142-3.

9. Roberto MS, Mearns K, Silva SA. Social and moral norm differences among Portuguese 1st and 6th year medical students towards their intention to comply with hand hygiene. Psychol Health Med 2012;17:408-16

10. Frenk J, Chen L, Bhutta ZA, Cohen J, Crisp N, Evans T, et al. Health professionals for a new century: transforming education to strengthen health systems in an interdependent world. Lancet 2010;376:1923-58.

11. Donaldson, the WHO Medical Education Team. World Alliance for Safer Care-WHO Patient Safety Curriculum Guide for Medical Schools. Geneva (Switzerland): World Health Organization; 2009. 